\title{
Baş Boyun Radyoterapisinde Farklı Tedavi Teknikleri İle Simultane Integre Boost Yönteminin Karşılaştırılması
}

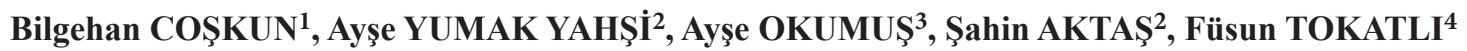 \\ ${ }^{1}$ Şişli Hamidiye Etfal Eğitim Araştırma Hastanesi, Radyasyon Onkolojisi Bölümü, Şişli-İstanbul \\ ${ }^{2}$ Marmara Üniversitesi, Fen Edebiyat Fakültesi, Fizik Bölümü, Kadıköy-İstanbul \\ ${ }^{3}$ Yeni Yüzyll Üniversitesi Gaziosmanpaşa Hastanesi, Radyasyon Onkolojisi Bölümü, Gaziosmanpaşa-İstanbul \\ ${ }^{4}$ Medicana International İstanbul Hastanesi, Radyasyon Onkolojisi Bölümü, Beylikdüzü-İstanbul
}

ÖZ

$\mathrm{Bu}$ çalışmada, baş boyun kanserlerinin tedavisinde kullanılan yoğunluk ayarlı radyoterapi ve yoğunluk ayarlı ark terapi tekniklerinin dozimetrik olarak karşılaşıtırılması amaçlanmıştır. Planlarda benzer planlama hedefleri ile 33 günlük fraksiyonlarla eş zamanlı olarak hedef hacimlerde farklı doz seviyelerinin sağlandığı Simultane Integre Boost tekniği kullanılmıştır. Planlar, 6 MV foton enerjisi kullanılarak, anisotropic analitic algoritması ile Eclipse tedavi planlama bilgisayarında hesaplatılmıştır. 9 Alan YART ve 2 Ark YAAT planlarının doz homojenitesi ve doz konformalitesi açısından daha üstün oldukları görülmektedir. Kritik organların doz değerleri incelendiğinde optik sinirler, kiazma, gözler, lensler ve parotisler için en düşük dozlar 7 ve 9 Alan YART planları ile elde edilirken beyin sapı, spinal kord, mandibula ve larenks için en iyi dozlar 2 Ark YAAT planları ile elde edilmiştir. Oral kavite dozu 1 Ark YAAT planları ile önemli ölçüde azaltılabilmektedir. Normal dokuda yüksek doz alan hacim değerleri ve ortalama normal doku doz değerleri 1 ve 2 Ark YAAT planları ile azalırken, normal dokuda düşük doz alan hacim değerleri azda olsa 1 ve 2 Ark planları ile artış göstermektedir. 1, 2 Ark YAAT ve 7, 9 Alan YART planları baş boyun kanserlerinde klinik olarak kabul edilebilir tedavi yöntemleridir. Tedavi süresinin kısalığı ve monitor unit değerlerinin düşük olması açısından YAAT planları daha avantajlıdır.

Anahtar kelimeler: Baş boyun kanserleri, simultane integre boost tekniği, yoğunluk ayarlı ark terapi, yoğunluk ayarlı radyoterapi

\section{Comparison of Simultaneous Integrated Boost Method for Different Treatments in Head and Neck Cancer Radiotherapy}

\begin{abstract}
A comparative planning study was undertaken to evaluate dosimetric differences between volumetric modulated arc therapy versus intensity modulated radiation therapy in the treatment of head and neck. Patients were investigated, with a standard prescription of three dose levels to the target volumes in 33 fractions. Simultaneous Integrated Boost technique was generated for all techniques, with similar planning objectives. Plans were calculated for $6 \mathrm{MV}$ photon using anisotropic analytical algorithm implemented in Eclipse treatment planning system. 9 field IMRT and 2 arc VMAT plans show superior dose homogeneity and dose conformity in PTVs. Doses to optic nerves, chiasm, eyes, lenses and protists were slightly lower in 7, 9 field IMRT plans. Doses to the brain stem, spinal cord, mandibula and larynx were better in the 2 arc VMAT techniques. Oral cavity dose reduced significantly with 1 arc VMAT. The high dose radiation volume to the normal tissue and the mean normal tissue dose decreased, but the low dose radiation volume increased slightly in the 1 and 2 arc VMAT plans. 1, 2 arc VMAT and 7, 9 field IMRT plans produced clinically acceptable treatment plan for the head and neck cancer. VMAT represents an attractive solution because of the shorter delivery time and the lower of monitor unit compared with IMRT.
\end{abstract}

Keywords: Head and neck cancer, simultaneous integrated boost technique, volumetric modulated arc therapy, intensity modulated radiation therapy 


\section{GİRIŞ}

Radyoterapi (RT), kanser hücrelerinin iyonlaştırıcı radyasyonla yok edilmesi veya çoğalmasının durdurulması temeline dayanır. Radyoterapinin amacı, tanımlanmış bir tümör hacmine, çevresindeki sağlıklı dokularda olabildiğince en az zarar oluşturacak şekilde mümkün olan en yüksek dozu vererek lokal kontrolün sağlanması ve hayat kalitesinin arttırılmasıdır [1-3]. Konvansiyonel RT (KRT) ile daha geniş alanlar alınarak sağlıklı dokuları korumak mümkün olamamaktadır. KRT' ye bir alternatif olarak gelişen yoğunluk ayarlı radyoterapi (YART) tekniği ile hedef hacimde en uygun doz dağılımı elde edilebilmektir. YART, üniform olmayan yoğunlukları, 1şın veya 'demetçik' denilen küçük demet alt birimlerine en optimal şekilde ayırabilmektedir. Her demetteki ışınların ayrı ayrı yoğunluğunu en optimal şekilde ayarlama yeteneği, radyasyon akısı üzerinde kontrolün artmasına izin vermekte ve optimum doz dağılımlarının özel olarak tasarlanmasını sağlamaktadır $[4,5]$. Radyasyon demet yoğunluğunu değiştirerek tümörlü dokuya maksimum doz verilirken, radyasyona duyarlı normal dokuları korumak mümkün olmaktadır. YART, standart üç boyutlu KRT (3BKRT) tekniklerine göre çok daha konformal doz dağ1lımları elde etmek için kullanılabilmektedir. Teorik olarak, planlanan hedef hacim (PTV) içerisindeki bu dağılımlar daha homojen hale getirilebilmekte ve istenirse alan kenarlarında daha hızlı doz düşüşü sağlanabilmektedir. YART tekniğinde hedef hacim içinde homojen olmayan bir doz dağılımı oluşmaktadır. Bu inhomojenite, bir veya daha fazla kritik organı kısmi ya da tam olarak koruma gereksiniminin ağır basmasından kaynaklanmaktadır. Çünkü homojenite kriteri normal yapıları koruma kriterinden daha az önemli sayılmaktadır. YART 3B hedefin ve diğer kritik yapıların şeklini ve sınırlarını daha yakın olarak saran konkav şekilli izodoz dağılımları sağlayabilmektedir. 3BKRT planlarındaki doz dağılımları konveks şekildedir ve bu durumda belirli hastalık bölgelerinin tedavisinde suboptimal kalabilmektedir. Bu gelişmiş doz dağılımları sayesinde, tümör kontrolünde artışa ve normal doku toksisitesinde azalmaya yol açabilmektedir [6,7]. Örneğin, baş ve boyun tümörlerinde yakındaki hassas kritik yapıları (örn. beyin sapı, spinal kord) korumak için genellikle konkav şekilli tedavi hacimleri gerekmektedir. Bu şekildeki demetlerin akısının dağılımları YART ile kolaylıkla elde edilebilmekte, ancak 3BKRT dahil diğer tekniklerle bunu elde etmek mümkün olmamaktadır. YART yönteminin temelinde, alt alanları oluştururken çok yapraklı kolimatör (MLC) sistemini kullanması yatmaktadır. YART yönteminde sözü edilen küçük alt alanlar, "leaf" adı verilen hızlı hareket edebilen kurşun yaprakçıkların belli bir gantri açısı içerisinde hareket etmesi ile oluşturulur. Bu küçük alt alanlar ile sadece istenilen hedef bölgenin ışınlanması sağlatılarak, ışınlanması istenmeyen normal dokuların korunması gerçekleşmiş olmaktadır.

YART teknikleri 3B doz dağılımını, belirli sabit doğrultularda çok sayıda bağımsız alan ya da tek veya birden fazla arkın üst üste bindirilmesi ile sağlamayı amaçlamaktadır [810]. $360^{\circ}$ ' lik tek bir gantri dönüşü ile tedavi planı optimizasyonunda tanımlanan hacme, istenen dozun uygulanması tekniği yoğunluk ayarlı ark terapi (YAAT) olarak isimlendirilir [11]. YAAT, tedavi alanının MLC' ler ile dinamik olarak şekillendirildiği bir tedavi tekniğidir. Bu yöntemde her bir alan segmentlere bölünür ve MLC' lerin her bir segment pozisyonunu alması sırasında gantri döner. Çok sayıda üst üste çakışan arklar, yaprakların düzenli açılarla (örn. $5^{0}$ ) yeni pozisyonlara hareket ettirilmesi ile sağlanır. Her ark her gantri açısındaki bir segmenti oluşturmak için programlanır. Bir sonraki segmenti oluşturmak için yeni bir ark başlatılır $[12,13]$.

Tüm hedef hacimler (gros hastalık, subklinik yayılımlar ve elektif tedavi edilen nodlar) eş zamanlı farklı fraksiyon büyüklükleri kullanılarak tedavi edilirse en konformal hale gelebilir. Bu tedavi stratejisine Simultane Integre Boost (SIB) denilmektedir [14-16]. SIB YART stratejisi sadece daha üstün doz dağılımları sağlamakla kalmayıp, aynı zamanda daha kolay, daha etkin ve muhtemelen daha hatasız bir YART planlama ve uygulama yöntemidir. Çünkü tüm tedavi boyunca aynı plan kullanılmaktadır. Ayrıca çoğu vakada elektron alanlarına gerek kalmamakta ve nodal hacimler YART alanlarına dahil edilebilmektedir. Entegre ek doz tedavisi, fraksiyon başına hedef hacme daha yüksek doz verirken, normal dokulara fraksiyon başına daha düşük doz verilebilmesi gibi ek radyobiyolojik avantajlar sağlamaktadır [17]. Fraksiyon başına yüksek doz ayrıca fraksiyon sayısını azaltmakta ve bu nedenle de tedavi maliyetinin düşürülmesi ve hastanın tedavi sırasındaki yükünü azaltmaktadır. Birçok bölgenin tedavisinde sürekli karşılaşılan alan çakışması sorunu [18] da bu yöntemle ortadan kalkmaktadır.

$\mathrm{Bu}$ çalışmada, Eclipse tedavi planlama sisteminde, 20 baş boyun bölgesi kanserli hastaya SIB yöntemi ile dört farklı (7 Alan YART, 9 Alan YART, 1 Ark YAAT ve 2 Ark YAAT) teknik kullanılarak hedef hacimler ve risk altındaki organların almış oldukları dozları doz hacim histogramı (DVH) yardımıyla değerlendirmeyi amaçladık.

Sonuçlar ile baş boyun RT' sinde kullanılan farklı tekniklerin hedef hacim ve risk altındaki organların doz dağılımları üzerindeki etkileri konusunda literatüre katkı sağlanacaktır. Farklı tekniklerde hedef hacim dışında kalan sağlıklı dokuların aldığı düşük doz hacimleri karşılaştırılarak, kullanılacak teknik belirlenirken sağlıklı dokuların maruz kalacakları dozların göz önüne alınabilmesi sağlanacaktır. Tedavi süresi 
açısından elde edilen istatistiksel verilerin, planlamadaki doz dağılımı açısından fark görülmeyen noktalarda, teknikler arasında seçim yapılmasını kolaylaştıran ve klinik uygulamada tedavi verimini arttıran faktörler olarak rol oynayacağ1 düşünülmektedir.

\section{MATERYAL VE YÖNTEM}

Çalışmada, Şişli Hamidiye Etfal Eğitim Araştırma Hastanesi Radyasyon Onkolojisi bölümünde daha önce baş boyun RT' si almış 20 hastaya (3 hipofarenks, 4 larenks, 2 orofarenks, 4 dil kökü, 3 nazofarenks, 2 parotis, 2 maksiller sinüs) ait bilgisayarlı tomografi (BT) görüntüleri kullanılmıştır. Hastaların immobilizasyonunda termoplastik baş boyun maskesi kullanılmıştır. Tedavi planlaması için BT tarama kalınlığı 3mm' dir. Görüntüler Digital Imaging and Communication in Medicine (DICOM) ile online olarak tedavi planlama sistemine aktarılmaktadır. Baş boyun bölgesinin ana görüntüleme araçları BT, magnetik rezonans (MR) ve pozitron emisyon tomografisi (PET)' dir. Görüntülemeler boynu içerecek şekildedir. Tüm görüntüleme tiplerinde koronal ve sagital kesitler değerlendirilmiştir. Hedef hacimlerin belirlenmesinde PET-CT veya MR görüntüleri, $\mathrm{CT}$ görüntüleri ile üst üste bindirilerek, hedef yapılar ve kritik organlar radyasyon onkologları tarafindan belirlenmiştir.

\subsection{Hedef Hacim ve Risk Altındaki Organların Tanımlanması}

Hedef hacimler olarak gros tümör hacmi (GTV54, GTV60, ,GTV70), klinik hedef hacmi (CTV54, CTV60, CTV70) ve PTV (PTV54, PTV60, PTV70) konturlanmıştır. GTV, klinik ve radyolojik olarak tanımlanan makroskobik tümör hacmidir. Sadece RT uygulanan hastalarda CTV70, radyolojik ve klinik bulgulara göre uygun marjlarla belirlenmiş sınırlarla nodal GTV' yi tanımlar. Postoperatif hastalarda CTV70, preoperatif GTV+tümörün yumuşak doku invazyonu veya metastatik lenf nodunun ekstrakapsüler uzanımını kapsayacak şekilde tümör ve rezeksiyon yatağını $0.5-1.5 \mathrm{~cm}$ marj ile içerir. Cerrahi yatak, preoperatif görüntüleme, cerrahi defektler veya postoperatif BT' deki cerrahi sonrası değişiklikleri kapsar. CTV60, sadece RT uygulanan hastalarda CTV70 ve klinik BT veya MR görüntülerindeki bulgulara göre CTV70' e komşu direkt tümör tutulumu olmayan yapıları içerir. Klinik veya radyolojik olarak saptanan tutulu lenf nodları $1 \mathrm{~cm}$ marj ile hava ve kemikler dişlanarak CTV60' a dahil edilir. Postoperatif hastalarda CTV60, profilaktik veya elektif boyun lenf nodu bölgesi olarak değerlendirilen klinik/radyolojik veya patolojik olarak tutulu olmayan servikal lenf nodlarını içerir. Sadece RT uygulanan hastalarda CTV54, profilaktik veya elektif boyun lenf nodu bölgesi olarak değerlendirilen klinik/radyolojik veya patolojik olarak tutulu olmayan servikal lenf nodlarını içerir. CTV hacimlerine

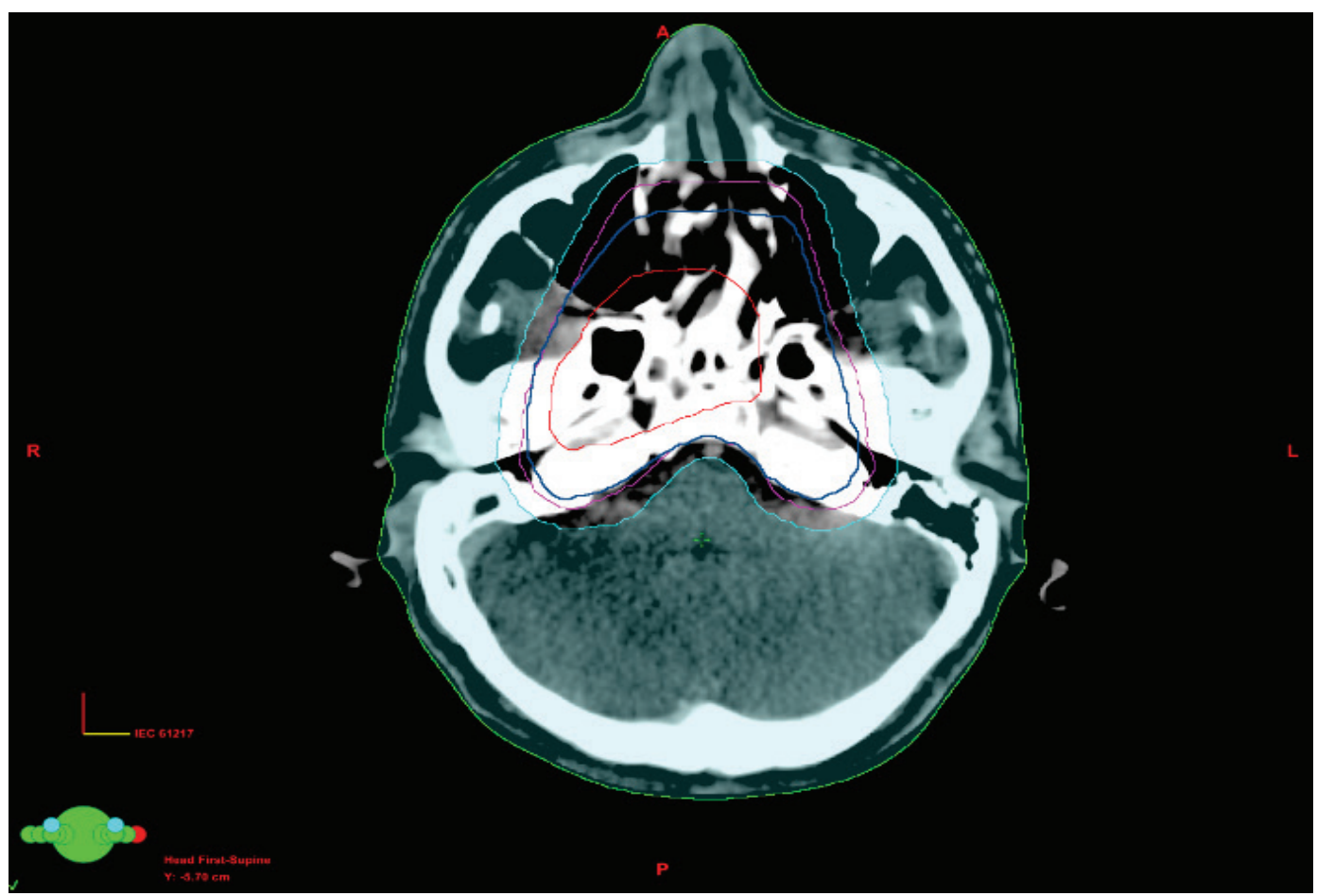

Şekil 1. Nazofarenks kanserli hastada PTV ve Body-PTV çizimi 
$0.5 \mathrm{~cm}$ marj verilerek PTV hacimleri oluşturulmuştur. Hasta planlamasına geçmeden önce hedef yapılar (PTV54, PTV60 ve PTV70) toplanarak toplam PTV oluşturulur ve Şekil 1' de gösterildiği gibi body konturundan $0.5 \mathrm{~cm}$ marjla çıartılarak Body-PTV oluşturulur. Böylece, PTV dışında kalan sağlıklı dokuların gereksiz doz alması engellenir.

Şekil 2' de gösterildiği gibi kritik organlar olarak sağ ve sol gözler, sağ ve sol lensler, sağ ve sol parotisler, oral kavite, mandibula, larenks, kiazma, beyin sapı, spinal kord, sağ ve sol optik sinirler konturlanmıştır. Keskin doz değişimlerinin rahatça sağlanabilmesi için hedef yapılar birbirlerinden $2 \mathrm{~mm}$ marjla çıkartılmıştır. Hedef yapıların içerisine giren kritik organların tümörle kesişmeyen kısımları $2 \mathrm{~mm}$ marjla çıkartılarak, ortalama doz değerlerinin düşürülmesi sağlanmıştır. Beyin sapı ve spinal kord için $5 \mathrm{~mm}$ marj verilerek planlama risk hacimi (PRV) oluşturulmuştur.

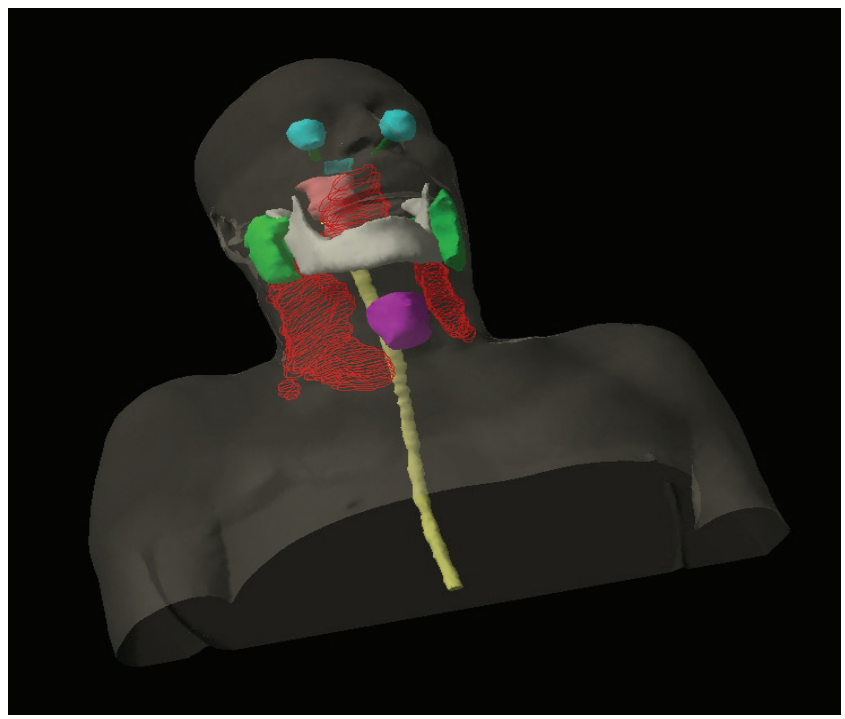

Şekil 2. Konturlanan hedef hacim ve kritik yapıların 3B görünümü

\subsection{Planlar Yapllırken Hedeflenen Doz Değerlerinin Belirlenmesi}

YART ve YAAT planlarında eş zamanlı olarak, farklı dokularda farklı doz seviyelerinin sağlandığı SIB tekniği kullanılmıştır. Eş zamanlı olarak yüksek riskli PTV' ye 6996cGy (fraksiyon başına 212cGy), orta riskli PTV' ye 6000cGy (fraksiyon başına 182cGy) ve düşük riskli PTV' ye 5400cGy (fraksiyon başına $164 \mathrm{cGy}$ ) uygulamak için 33 günlük fraksiyonlar kullanılmıştır.

Kritik organlar için Radiation Therapy Oncology Group (RTOG) 0022, 0225, 1016, 1008, 0920 ve 0912 baş boyun protokolleri [19] referans alınd.
Risk altındaki organlar için hedeflenen doz sınırları ise aşağıda verilmiştir;

- Beyin sap1;

$<52$ Gy herhangi hacim $>0,03 \mathrm{cc}$

- Kiazma;

- Spinal kord; maksimum $\leq 54 \mathrm{~Gy}$

kord; $\quad<48$ Gy herhangi hacim $>0,03 \mathrm{cc}$

- Optik sinir; PRV $<50$ Gy herhangi hacim $>0,01 \mathrm{cc}$

- Göz;

- Lens; maksimum $\leq 54$ Gy ortalama $<35 \mathrm{~Gy}$ olabildiğince düşük maksimum doz değerleri elde edilmelidir.

- Parotis; bir bez korunuyorsa; ortalama $<26$ Gy veya $\% 50<30$ Gy

- Oral kavite; ortalama<40Gy

- Mandibula; maksimum<66Gy

- Larenks; maksimum $<50$ Gy

\subsection{YART ve YAAT Planlarının Yapılışı}

$\mathrm{Bu}$ çalışmada, SIB-YART ve SIB-YAAT teknikleriyle baş boyun kanserli hastalara yedi ve dokuz koplanar alanlı dinamik YART, bir tam ark ve iki tam ark YAAT tedavi planlamaları oluş̧uruldu. 7 Alan YART planlarında, $51^{0}$ ' lik eşit aralıklı gantri açıları $\left(0^{0}, 51^{0}, 102^{0}, 153^{0}, 204^{0}, 255^{0}, 306^{0}\right)$, 9 Alan YART planlarında, $40^{\circ}$ ' lik eşit aralıklı gantri açıları $\left(0^{\circ}, 40^{\circ}, 80^{\circ}, 120^{\circ}, 160^{\circ}, 200^{\circ}, 240^{\circ}, 280^{\circ}, 320^{\circ}\right)$ kullanild. 1 Ark YAAT planları gantrinin tek bir dönüşü $\left(179^{0}-181^{\circ}\right)$ ile oluşturulurken, 2 Ark YAAT planları birbirine ters yönlerde gantri dönüş açılarına $\left(179^{0}-181^{0}, 181^{0}-179^{\circ}\right)$ sahip planlarla oluşturuldu. 2 arklı planlarda arklar birbirine ters yönde $30^{\circ}$ ve $330^{\circ}$ " lik kolimatör açıları ile oluşturularak MLC' lerden kaynaklanacak sizıntı ve "tongue and groove" etkisinin [20] minimuma indirilmesi amaçlanmıştır. Alanlar belirlendikten sonra optimizasyon işlemine geçildi. Tedavi planı optimizasyonu aşamasında, hedef hacimlere minimum ve maksimum doz sınırlamaları yapılarak PTV' lerin \%95' inin tanımlanan dozun \%100' ünü almasına çalışıldı. Riskli organlara belirlenen kriterler arasında en düşük dozu verebilmek için gerekli doz sınırlamaları yapıldı. Eğer planda iyileştirme yapmak gerekli ve mümkün ise, objektif fonksiyon değerleri değiştirilmekte ve tatmin edici bir tedavi planı elde edene kadar optimizasyon işlemi tekrar edilmektedir. Optimizasyon ve doz dağılımının hesaplanması sonrasında YART planlarında her alana genel fluence düzeltmesi uygulanarak MLC hareketleri düzgünleştirildi.

Bütün planlar, 6MV foton enerjisi kullanılarak, 120 yaprak millenium MLC' li Varian Clinac iX model lineer hizlandırıcı parametreleriyle oluşturulmuştur ve anisotropic analitic algoritması (AAA v.10.28) ile Eclipse tedavi planlama bilgisayarında hesaplatılmıştır. 


\subsection{Tedavi Planlarının Karşılaş̧tıılması}

Tüm tedavi planlarının hedef hacim, risk altındaki organ ve sağlıklı doku dozlarının karşılaştırılmasında DVH' ler kullanıldı. Hedef hacim içinde soğurulan doz dağılımının düzgünlüğünü karakterize etmek için ICRU' nun 83 numaralı raporunda [6] belirtilen denklem (1)' deki homojenite indeks eşitliği kullanıldı.

$$
\mathrm{HI}=\left(\mathrm{D}_{\% 2}-\mathrm{D}_{\% 98}\right) / \mathrm{D}_{\% 50}(1)
$$

$\mathrm{D}_{\% 2}$ PTV' lerin \%2' sinin almış olduğu doz olup maksimum dozu, $\mathrm{D}_{\% 98}$ PTV' lerin \%998' inin almış olduğu doz olup minimum dozu ve $\mathrm{D}_{\% 50}$ PTV' lerin \%50' sinin almış olduğu dozu göstermektedir. Yüksek doz bölgesinin hedef hacim ile uyumunu belirlemek amaciyla Van't Riet ve ark. [21] tarafindan tanımlanan, hem hedef hacim hem de sağlıklı doku terimlerini barındıran denklem (2)' deki konformalite indeks eşitliği kullanıldı.

$$
\mathrm{CI}=\left(\mathrm{TV}_{\mathrm{RI}} / \mathrm{TV}\right) \mathrm{x}\left(\mathrm{TV}_{\mathrm{RI}} / \mathrm{V}_{\mathrm{RI}}\right)
$$

$\mathrm{TV}_{\mathrm{RI}}$ referans izodoz ile kapsanan hedef hacmi, TV hedef hacmi ve $\mathrm{V}_{\mathrm{RI}}$ referans izodoz hacmini göstermektedir. Ayrica, PTV' ye ait DVH' ler kullanılarak hedef hacme ait $\mathrm{D}_{\text {min }}(\mathrm{cGy}), \mathrm{D}_{\text {max }}(\mathrm{cGy}), \mathrm{D}_{\text {ort }}(\mathrm{cGy})$ (hedef hacimde minimum, maksimum ve ortalama dozlar), $\mathrm{V}_{105}(\%), \mathrm{V}_{107}(\%), \mathrm{V}_{110}(\%)$ (tanımlanan dozun \%105, \%107 ve \%110' unu alan hacim) verileri karşılaştırılmıştır. Kritik organlarda optik sinirler, kiazma, beyin sapı ve spinal kord için maksimum doz $\left(D_{\max }(G y)\right)$, gözler, lensler, parotisler, mandibula, oral kavite ve larenks için ortalama doz $\left(\mathrm{D}_{\text {ort }}(\mathrm{cGy})\right)$ değerleri karşılaştırılmıştır. Sağlıklı dokuların maruz kaldığı dozların, kullanılan tedavi tekniklerine bağlı farklılıklarının belirlenmesinde Body-PTV' ye ait DVH' ler kullanılarak $\mathrm{D}_{\text {ort }}$ (Gy) (sağlıklı dokuda oluşan ortalama doz), $\mathrm{V}_{5}(\%), \mathrm{V}_{10}(\%), \mathrm{V}_{15}(\%)$ ve $\mathrm{V}_{20}(\%)$ (sağlıklı dokuda 5Gy, 10Gy, 15Gy ve 20Gy doz alan hacmin yüzdesi) değerleri karşılaştırılmıştır. Bunlara ek olarak her bir planlama tekniğine ait MU ve tedavi sürelerinin karşılaştırılması yapılmıştır.

Çalışmadaki araştırma verileri SPSS (Statistical Package for the Social Sciences) version 23 ile değerlendirilmiştir. 4 farklı tedavi planlama tekniğinde verilerin gruplar arası ikili karşılaştırmalarında, parametrik koşullar sağlanıyorsa "Paired-Samples T" testi, sağlanamıyorsa "Mann-Whitney U" testi kullanıldi.

\section{BULGULAR VE TARTIŞMA}

Baş boyun kanserlerinin tedavisinde radyoterapi önemli bir yere sahiptir. Gerek erken ve lokal ileri evre tümörlerde primer tedavi yöntemi olarak gerekse lokal ileri evre tümörlerde postoperatif olarak kullanılmaktadır. Baş boyun bölgesi anatomisinin kompleks oluşu bir çok risk altındaki organı barındırması radyoterapi planlamasını güçleştirmektedir. Düzensiz hedef hacimlere yüksek dozların tanımlandığı ve hedef hacim etrafinda korunması gereken birçok sağlıklı dokuyu barındıran baş boyun bölgesi kanserlerinin radyoterapisinde, YART ve YAAT tekniklerinin karşıllaştırılıp, birbirlerine göre avantaj ve dezavantajları bu çalışmada araştırılmıştır.

Tablo 1' de 20 baş boyun hastası için 7 ve 9 Alan YART, 1 ve 2 Ark YAAT tedavi planlamalarından elde edilen PTV70, PTV60, PTV54' e ait doz değerlerinin ortalamaları ve HI, $\mathrm{CI}$ değerlerinin ortalamaları, $\mathrm{MU}$ ve tedavi süreleri için ortalama sayısal değerler ile teknikler arası ikili istatistiksel analiz sonuçları verilmektedir.

PTV70 hedef hacmin tanımlanan doz ile kapsanması açısindan 7 Alan YART, 9 Alan YART ve 2 Ark YAAT planlama teknikleri 1 Ark YAAT planlama tekniğine göre daha avantajlıdır. HI' nın en ideal değeri " 0 ” olduğundan en homojen doz dağılımının oluştuğu teknikler 9 Alan YART $(\mathrm{HI}=0,0755)$ ve 2 Ark YAAT $(\mathrm{HI}=0,079)$ olarak bulunmuştur. Krishnan J. ve arkadaşlarının çalışmasında [22] baş boyun kanserli 22 hasta için 9 Alan YART ile 2 Ark YAAT teknikleri karşılaştırılmış, PTV70 HI değeri açısından bizim çalışmamızla uyumlu olarak 9 Alan YART ve 2 Ark YAAT teknikleri arasında anlamlı fark olmadığı görülmüştür. CI' nın en ideal değeri " 1 " olduğundan en konformal teknik 2 Ark YAAT $(\mathrm{CI}=1,036)$ olarak bulunmuştur. Bu sonuç, Krishnan J. ve arkadaşlarının çalışması ile desteklenmektedir [22].

PTV60 hedef hacmin tanımlanan doz ile kapsanması açısindan 9 Alan YART ve 2 Ark YAAT planlama teknikleri 7 Alan YART ve 1 Ark YAAT planlama tekniklerine göre daha avantajlıdır. En homojen doz dağılımının oluştuğu teknik 9 Alan YART $(\mathrm{HI}=0,1036)$ olarak bulunmuştur. Boylan C. ve arkadaşlarının çalışmasında [23] baş boyun kanseri 10 hasta için 7 Alan YART ve 2 Ark YAAT teknikleri karşılaştııılmış, PTV60 HI değeri açısından bizim çalışmamızla uyumlu olarak 7 Alan YART ve 2 Ark YAAT teknikleri arasında anlamlı fark olmadığı görülmüş̧ür.

PTV54 hedef hacminin tanımlanan doz ile kapsanması açısından 7 Alan YART, 9 Alan YART ve 2 Ark YAAT planlama teknikleri 1 Ark YAAT planlama tekniğine göre daha avantajlıdır. En homojen doz dağılımının oluştuğu teknik 2 Ark YAAT $(\mathrm{HI}=0,1334)$ olarak bulunmuştur. Bu sonuç, Krishnan J. ve arkadaşlarının [22] 9 Alan YART ile 2 Ark YAAT tekniklerinin karşılaştırılması ve Syam Kumar S.A. ve arkadaşlarının [24] 9 Alan YART ile 1 ve 2 Ark YAAT tekniklerinin karşılaştırılması çalışması ile desteklenmektedir. 
Tablo 1. 20 baş boyun hastası için, dört farklı planlama tekniğinden elde edilen, hedef hacimlere ait ortalama doz, hacim değerleri, ortalama HI, CI, MU, tedavi süreleri ve teknikler arasındaki istatistiksel analiz sonuçları

\begin{tabular}{|c|c|c|c|c|c|c|c|c|c|c|}
\hline & $\begin{array}{l}7 \text { Alan } \\
\text { YART }\end{array}$ & $\begin{array}{l}\text { 9 Alan } \\
\text { YART }\end{array}$ & $\begin{array}{l}1 \text { Ark } \\
\text { YAAT }\end{array}$ & $\begin{array}{l}2 \text { Ark } \\
\text { YAAT }\end{array}$ & $\mathbf{p}$ & p* & $\mathrm{p}^{* *}$ & $\mathrm{p}^{* * *}$ & $p^{* * * *}$ & $\mathbf{p}^{* * * * *}$ \\
\hline \multicolumn{11}{|l|}{ PTV70 } \\
\hline $\mathrm{D}_{\min }(\mathrm{cGy})$ & 6184,0 & 6203,4 & 6180,0 & 6272,3 & 0,629 & 0,950 & 0,165 & 0,722 & 0,262 & 0,012 \\
\hline $\mathrm{D}_{\max }(\mathrm{cGy})$ & 7620,5 & 7582,1 & 7825,6 & 7636,6 & 0,017 & 0 & 0,614 & 0 & 0,063 & 0 \\
\hline $\mathrm{D}_{\text {ort }}(\mathrm{cGy})$ & 7261,3 & 7246,6 & 7322,5 & 7262,7 & 0,078 & 0,002 & 0,933 & 0 & 0,337 & 0 \\
\hline $\mathrm{D}_{2}(\mathrm{cGy})$ & 7469,9 & 7443 & 7590,6 & 7474,2 & 0,005 & 0 & 0,868 & 0 & 0,202 & 0 \\
\hline $\mathrm{D}_{98}(\mathrm{cGy})$ & 6872,5 & 6884,2 & 6877,3 & 6899,2 & 0,035 & 0,763 & 0,037 & 0,657 & 0,288 & 0 \\
\hline $\mathrm{D}_{50}(\mathrm{cGy})$ & 7287,2 & 7272 & 7353,1 & 7288,7 & 0,068 & 0,005 & 0,944 & 0,002 & 0,471 & 0 \\
\hline $\mathrm{V}_{105}(\%)$ & 26,07 & 23,52 & 50,57 & 31,74 & 0,112 & 0,001 & 0,386 & 0 & 0,229 & 0 \\
\hline $\mathrm{V}_{107}(\%)$ & 7,17 & 5,44 & 19,36 & 5,55 & 0,537 & 0,001 & 0,321 & 0 & 0,123 & 0,001 \\
\hline $\mathrm{V}_{110}(\%)$ & 0,06 & 0 & 1,43 & 0,05 & 0,264 & 0,002 & 0,672 & 0 & 0,515 & 0,001 \\
\hline $\mathrm{HI}$ & 0,0809 & 0,0755 & 0,0957 & 0,0790 & 0 & 0,008 & 0,695 & 0,001 & 0,405 & 0 \\
\hline CI & 1,107 & 1,083 & 1,095 & 1,036 & 0 & 0,499 & 0 & 0,544 & 0,009 & 0 \\
\hline \multicolumn{11}{|l|}{ PTV60 } \\
\hline $\mathrm{D}_{\text {ort }}(\mathrm{cGy})$ & 6728,9 & 6720,3 & 6771,1 & 6702,2 & 0,205 & 0,080 & 0,177 & 0,029 & 0,328 & 0 \\
\hline $\mathrm{D}_{2}(\mathrm{cGy})$ & 6765,3 & 6679,1 & 6847,5 & 6691,8 & 0,102 & 0,036 & 0,029 & 0,011 & 0,811 & 0 \\
\hline $\mathrm{D}_{98}(\mathrm{cGy})$ & 5995,0 & 6020,2 & 5929,3 & 5942,2 & 0,008 & 0,098 & 0,135 & 0,036 & 0,047 & 0,345 \\
\hline $\mathrm{D}_{50}(\mathrm{cGy})$ & 6378,8 & 6360,6 & 6435,2 & 6354,1 & 0,091 & 0,085 & 0,332 & 0,029 & 0,801 & 0 \\
\hline $\mathrm{HI}$ & 0,1209 & 0,1036 & 0,1427 & 0,1180 & 0,039 & 0 & 0,394 & 0 & 0,046 & 0 \\
\hline \multicolumn{11}{|l|}{ PTV54 } \\
\hline $\mathrm{D}_{\text {ort }}(\mathrm{cGy})$ & 6205,7 & 6201,9 & 6235,3 & 6162,1 & 0,596 & 0,297 & 0,101 & 0,248 & 0,145 & 0 \\
\hline $\mathrm{D}_{2}(\mathrm{cGy})$ & 6201,2 & 6171,7 & 6258,1 & 6064,1 & 0,073 & 0,173 & 0,001 & 0,091 & 0,027 & 0 \\
\hline $\mathrm{D}_{98}(\mathrm{cGy})$ & 5274,1 & 5299,9 & 5228,9 & 5300,2 & 0,003 & 0,146 & 0,279 & 0,044 & 0,989 & 0 \\
\hline $\mathrm{D}_{50}(\mathrm{cGy})$ & 5738,6 & 5730,5 & 5808,9 & 5731,6 & 0,369 & 0,027 & 0,792 & 0,019 & 0,970 & 0 \\
\hline $\mathrm{HI}$ & 0,1616 & 0,1519 & 0,1773 & 0,1334 & 0,039 & 0 & 0,394 & 0 & 0,014 & 0 \\
\hline $\begin{array}{l}\text { MU } \\
\text { Tedavi }\end{array}$ & 1492 & 1617 & 566 & 568 & 0,079 & 0 & 0 & 0 & 0 & 0,860 \\
\hline Süresi(s) & 472 & 517 & 191 & 338 & 0 & 0 & 0 & 0 & 0 & 0 \\
\hline
\end{tabular}

p -7 Alan YART ile 9 Alan YART teknikleri arasındaki istatistiksel analiz; p* - 7 Alan YART ile 1 Ark YAAT teknikleri arasındaki istatistiksel analiz; $\mathrm{p}^{* *}$ - 7 Alan YART ile 2 Ark YAAT teknikleri arasındaki istatistiksel analiz; $\mathrm{p}^{* * *}$ - 9 Alan YART ile 1 Ark YAAT teknikleri arasindaki istatistiksel analiz; $\mathrm{p}^{* * * *}$ - 9 Alan YART ile 2 Ark YAAT teknikleri arasındaki istatistiksel analiz; p***** 1 Ark YAAT ile 2 Ark YAAT teknikleri arasındaki istatistiksel analiz.

Ortalama tedavi süresi bakımından, dört teknik arasında istatistiksel olarak anlamlı fark vardır $(p<0,05)$. En uzun tedavi süresine sahip tedavi planlama tekniği 9 Alan YART, en kısa tedavi süresine sahip tedavi planlama tekniği ise 1 Ark YAAT olarak bulunmuştur. Krishnan J. ve arkadaşlarının çalışmasında aynı şekilde YAAT tekniğinde tedavi süresi YART tekniğine göre anlamlı olarak daha kısa bulunmuştur $(p=0,00001)$ [22]. Ortalama MU değeri bakımından, en büyük değere sahip tedavi planlama tekniği 9 Alan YART, en küçük değere sahip tedavi planlama tekniği ise 1 Ark YAAT olarak bulunmuştur. YART teknikleri ile YAAT teknikleri arasında istatistiksel olarak anlamlı fark vardır $(p<0,05)$.
Bu sonuç, Syam Kumar S.A. ve arkadaşlarının çalışması ile desteklenmektedir [24].

Tablo 2' de 20 baş boyun hastası için 7 ve 9 Alan YART, 1 ve 2 Ark YAAT tedavi planlamalarından elde edilen sağ optik sinir, sol optik sinir, kiazma, beyin sap1 ve spinal kord için ortalama $\mathrm{D}_{\text {max }}(\mathrm{cGy})$ değerleri ile să̆ göz, sol göz, să̆ lens, sol lens, sağ parotis, sol parotis, oral kavite, mandibula ve larenks için ortalama $\mathrm{D}_{\text {ort }}(\mathrm{cGy})$ değerleri, sağlıklı dokuda oluşan $\mathrm{D}_{\text {ort }}(\mathrm{cGy}), \mathrm{V}_{5}(\%), \mathrm{V}_{10}(\%), \mathrm{V}_{15}(\%)$ ve $\mathrm{V}_{20}(\%)$ değerlerinin ortalamaları ve teknikler arası ikili istatistiksel analiz sonuçları verilmektedir. 
Tablo 2. 20 baş boyun hastası için, dört farklı planlama tekniğinden elde edilen, kritik organlar için ortalama doz değerleri, sağlıklı dokuda ortalama doz ve hacim değerleri ile teknikler arasındaki istatistiksel analiz sonuçları

\begin{tabular}{|c|c|c|c|c|c|c|c|c|c|c|}
\hline & $\begin{array}{l}7 \text { Alan } \\
\text { YART }\end{array}$ & $\begin{array}{l}\text { 9 Alan } \\
\text { YART }\end{array}$ & $\begin{array}{l}1 \text { Ark } \\
\text { YAAT }\end{array}$ & $\begin{array}{l}2 \text { Ark } \\
\text { YAAT }\end{array}$ & $\mathbf{p}$ & $p^{*}$ & $\mathrm{p}^{* *}$ & $\mathrm{p}^{* * *}$ & $\mathbf{p}^{* * * *}$ & $\mathbf{p}^{* * * * *}$ \\
\hline \multicolumn{11}{|l|}{$\mathbf{D}_{\max }(\mathbf{c G y})$} \\
\hline Sağ Optik Sinir & 1426,0 & 1387,3 & 1482,5 & 1455,3 & 0,296 & 0,044 & 0,037 & 0,002 & 0,009 & 0,232 \\
\hline Sol Optik Sinir & 1306,2 & 1301,6 & 1439,5 & 1446,1 & 0,191 & 0,002 & 0,002 & 0,001 & 0,002 & 0,852 \\
\hline Kiazma & 1441,9 & 1401,2 & 1611,4 & 1564,6 & 0,008 & 0,011 & 0,030 & 0,006 & 0,006 & 0,136 \\
\hline Beyin Sap1 & 4593,5 & 4507,4 & 4757,8 & 4439,9 & 0,070 & 0,119 & 0,078 & 0,033 & 0,485 & 0 \\
\hline Spinal Kord & 4342,4 & 4288,0 & 4347,9 & 4173,1 & 0,436 & 0,971 & 0,143 & 0,693 & 0,374 & 0,025 \\
\hline \multicolumn{11}{|l|}{$D_{\text {ort }}(\mathbf{c G y})$} \\
\hline Sağ Göz & 593,6 & 587,2 & 688,5 & 658,3 & 0,491 & 0,110 & 0,216 & 0,048 & 0,057 & 0,012 \\
\hline Sol Göz & 506,3 & 545,9 & 583,5 & 589,5 & 0,221 & 0,236 & 0,214 & 0,298 & 0,250 & 0,594 \\
\hline Sağ Lens & 329,0 & 321,3 & 412,4 & 363,8 & 0,506 & 0,084 & 0,230 & 0,023 & 0,086 & 0,014 \\
\hline Sol Lens & 358,2 & 348,7 & 371,9 & 402,4 & 0,641 & 0,787 & 0,508 & 0,568 & 0,352 & 0,127 \\
\hline Sağ Parotis & 2243,5 & 2285,2 & 2533,1 & 2307,5 & 0,253 & 0,013 & 0,572 & 0,070 & 0,867 & 0 \\
\hline Sol Parotis & 2278,2 & 2298,6 & 2475,1 & 2325,1 & 0,522 & 0,031 & 0,708 & 0,058 & 0,847 & 0,001 \\
\hline Oral Kavite & 4259,2 & 4320,9 & 3925,3 & 3984,9 & 0,383 & 0,001 & 0,006 & 0,001 & 0,001 & 0,171 \\
\hline Mandibula & 4874,4 & 4838,0 & 4405,1 & 4396,4 & 0,106 & 0 & 0 & 0 & 0 & 0,644 \\
\hline Larenks & 3676,7 & 3680,9 & 3699,6 & 3620,0 & 1 & 0,745 & 1 & 0,765 & 0,849 & 0,745 \\
\hline \multicolumn{11}{|l|}{ Sağlıklı Doku } \\
\hline $\mathrm{D}_{\text {ort }}(\mathrm{cGy})$ & 829,73 & 840,73 & 814,80 & 811,57 & 0,019 & 0,079 & 0,062 & 0,007 & 0,006 & 0,337 \\
\hline $\mathrm{V}_{5}(\%)$ & 32,94 & 32,77 & 34,44 & 34,77 & 0,294 & 0 & 0 & 0 & 0 & 0,064 \\
\hline $\mathrm{V}_{10}(\%)$ & 24,79 & 24,65 & 24,66 & 25,29 & 0,643 & 0,717 & 0,134 & 0,995 & 0,129 & 0,058 \\
\hline $\mathrm{V}_{15}(\%)$ & 20,81 & 20,94 & 20,15 & 20,26 & 0,376 & 0,015 & 0,042 & 0,001 & 0,018 & 0,422 \\
\hline $\mathrm{V}_{20}(\%)$ & 17,55 & 17,39 & 16,28 & 16,22 & 0,274 & 0 & 0,001 & 0 & 0,001 & 0,695 \\
\hline
\end{tabular}

p -7 Alan YART ile 9 Alan YART teknikleri arasındaki istatistiksel analiz; p* - 7 Alan YART ile 1 Ark YAAT teknikleri arasındaki istatistiksel analiz; p** - 7 Alan YART ile 2 Ark YAAT teknikleri arasındaki istatistiksel analiz; p*** - 9 Alan YART ile 1 Ark YAAT teknikleri arasındaki istatistiksel analiz; $\mathrm{p}^{* * * *}$ - 9 Alan YART ile 2 Ark YAAT teknikleri arasındaki istatistiksel analiz; p***** - 1 Ark YAAT ile 2 Ark YAAT teknikleri arasındaki istatistiksel analiz.

Seri kritik organ (sağ optik sinir, sol optik sinir, kiazma, beyin sap1 ve spinal kord) ve paralel kritik organ (sağ göz, sol göz, sağ lens, sol lens, sağ parotis, sol parotis, oral kavite, mandibula ve larenks) dozları 7-9 Alan YART ve 1-2 Ark YAAT planlama teknikleri ile tolerans limitlerinin altında bulunmuştur. 7-9 Alan YART tekniklerinde sağ ve sol optik sinir ortalama $\mathrm{D}_{\text {max }}(\mathrm{cGy})$ değerleri 1-2 Ark YAAT tekniklerine göre anlamlı olarak daha küçük bulunmuştur. Kiazma ortalama $\mathrm{D}_{\max }(\mathrm{cGy})$ değeri 9 Alan YART tekniğinde diğer tekniklere göre anlamlı olarak daha küçük bulunmuştur.
Beyin sapı için ortalama $\mathrm{D}_{\max }(\mathrm{cGy})$ değeri bakımından, en büyük değere sahip tedavi planlama tekniği 1 Ark YAAT, en küçük değere sahip tedavi planlama tekniği ise 2 Ark YAAT olarak bulunmuştur. Sonuç olarak, 7-9 Alan YART ve 2 Ark YAAT tekniklerinde beyin sapı ortalama $D_{\text {max }}$ (cGy) değeri 1 Ark YAAT tekniğine göre daha küçük bulunmuştur. Syam Kumar S.A. ve arkadaşları çalışmalarında [24] YART ve YAAT teknikleri arasında beyin sapı ortalama $\mathrm{D}_{\max }(\mathrm{cGy})$ değeri bakımından anlamlı fark olmadığını belirtmişlerdir. Spinal kord ortalama $\mathrm{D}_{\max }(\mathrm{cGy})$ değeri açısından planlar 
arasında önemli farklar görülmezken, en düşük doz değeri 2 Ark YAAT tekniği ile elde edilmiştir. Boylan C. ve arkadaşlarının [23] ve White P. ve arkadaşlarının çalışmalarında [25] baş boyun kanserli hastalar için 7 Alan YART ile 2 Ark YAAT teknikleri karşılaştırılmış, beyin sapı ve spinal kord $\mathrm{D}_{\max }(\mathrm{cGy})$ değeri açısından çalışmamızla uyumlu olarak teknikler arasında anlamlı fark olmadığı görülmüştür.

7-9 Alan YART ve 2 Ark YAAT tekniklerinde sağ göz, sağ lens, sağ parotis ve sol parotis ortalama $\mathrm{D}_{\text {ort }}(\mathrm{cGy})$ değerleri 1 Ark YAAT tekniğine göre daha küçük bulunmuştur. Sol göz, sol lens ve larenks ortalama $\mathrm{D}_{\text {ort }}(\mathrm{cGy})$ değerleri bakımından, teknikler arasında istatistiksel olarak anlamlı fark bulunamamıştır. Boylan C. ve arkadaşlarının çalışmasinda [23] sağ göz, sol göz, sağ parotis, sol parotis ve larenks $\mathrm{D}_{\text {ort }}(\mathrm{cGy})$ değerleri açısından istatistiksel değerlendirmede, bizim çalışmamızla uyumlu olarak 7 Alan YART ve 2 Ark YAAT teknikleri arasında anlamlı fark olmadığı görülmüştür. 1-2 Ark YAAT tekniklerinde oral kavite ve mandibula ortalama $\mathrm{D}_{\text {ort }}$ (cGy) değerleri 7-9 Alan YART tekniklerine göre anlamlı olarak daha küçük bulunmuştur. Benzer şekilde, Krishnan J. ve arkadaşlarının çalışmasında [22] 2 Ark YAAT tekniğinde oral kavite $\mathrm{D}_{\text {ort }}(\mathrm{cGy})$ değeri 9 Alan YART tekniğine göre anlamlı olarak daha küçük bulunmuştur. Mandibula için bulunan değerler, Syam Kumar S.A. ve arkadaşları tarafından yapılan çalışmanın sonuçları ile uyumludur [24].

Sağlıklı dokuların aldığı dozlar için, $\mathrm{V}_{5}(\%)$ değeri açısindan YART teknikleri YAAT tekniklerine göre daha avantajlı bulunurken, $\mathrm{V}_{10}(\%)$ değeri açısından teknikler arasında istatistiksel olarak anlamlı fark bulunamamıştır. $\mathrm{D}_{\text {ort }}(\mathrm{cGy})$, $\mathrm{V}_{15}(\%)$ ve $\mathrm{V}_{20}(\%)$ değerleri açısından YAAT tekniklerinin YART tekniklerine göre daha avantajlı olduğu bulunmuştur. Krishnan J. ve arkadaşlarının çalışmasında [22] sağlıklı dokuda oluşan $\mathrm{D}_{\text {ort }}(\mathrm{cGy})$ ve $\mathrm{V}_{5}(\%)$ değerleri için ve Syam Kumar S.A. ve arkadaşlarının çalışmasında [24] $\mathrm{D}_{\text {ort }}(\mathrm{cGy})$, $\mathrm{V}_{10}(\%)$ ve $\mathrm{V}_{15}(\%)$ değerleri için YART ve YAAT teknikleri arasında istatistiksel değerlendirmede anlamlı fark olmadığ görülmüştür. Ortalama $\mathrm{V}_{20}(\%)$ değeri açısından bulduğumuz değerler Syam Kumar S.A. ve arkadaşları tarafından yapılan çalışmanın sonuçları ile uyumludur [24].

\subsection{Sonuçlar ve Değerlendirmeler}

7 Alan YART, 9 Alan YART, 1 Ark YAAT ve 2 Ark YAAT tekniklerini kullanarak elde ettiğimiz tüm planlamalar, hedef hacim ve riskli organlar açısından kabul edilebilir doz sınırları içindedir. 9 Alan YART ve 2 Ark YAAT tekniklerinin hedef hacimdeki minimum, maksimum ve ortalama dozlar açısından baş boyun kanserli hastalarda 7 Alan YART ve 1 Ark YAAT tekniklerine göre biraz daha üstün oldukları görülmüştür. Hedef hacim ile reçete edilen doz hacmi arasındaki uyumu analiz etmek amacıyla kullanılan CI ve hedef hacim içindeki doz dağılımını değerlendirmek için kullanılan HI değerleri açısından 9 Alan YART ve 2 Ark YAAT tekniklerinin daha iyi sonuçlar verdiği bulunmuştur. Kritik organların $\mathrm{D}_{\text {max }}(\mathrm{cGy})$ değerleri incelendiğinde; sağ optik sinir, sol optik sinir ve kiazma için en düşük değerler 9 Alan YART planları ile elde edilirken, beyin sapı ve spinal kord için ise en düşük değerler 2 Ark YAAT planları ile elde edilmiştir. Kritik organların $\mathrm{D}_{\text {ort }}(\mathrm{cGy})$ değerleri incelendiğinde; sağ göz ve sağ lens için 9 Alan YART, sağ parotis ve sol parotis için 7 Alan YART, oral kavite için 1 Ark YAAT, mandibula için ise 2 Ark YAAT planları ile en düşük ortalama doz değerleri elde edilmiştir. Sol göz, sol lens ve larenks için ortalama doz değerleri açısından teknikler arasında istatistiksel olarak anlamlı fark olmadığı görülmüştür. Yüksek doz alan sağlıklı doku hacmi ( $\mathrm{D}_{\text {ort }}(\mathrm{cGy}), \mathrm{V}_{15}(\%)$ ve $\mathrm{V}_{20}(\%)$ ) YAAT planlarında anlamlı olarak daha düşükken, düşük doz ile ışınlanan sağlıklı doku hacmi $\left(\mathrm{V}_{5}(\%)\right)$ değeri YART planlarında anlamlı olarak daha düşük bulunmuştur. YART planlarındaki MU değerleri YAAT planlarındaki MU değerlerine göre \%38 daha fazladır. Tedavi süresinin kısalığı ve MU değerlerinin daha düşük olması açısından YAAT planları hasta için daha uygundur ve klinik uygulamada daha avantajlıdır. Hastanın durumuna ve radyasyon onkolojisi kliniğinin teknik şartlarına bağlı olarak dört tekniğin de uygulanabilir olduğu gösterilmiştir. İdeali her hastayı ayrıntılı olarak değerlendirip hasta bazında tedavi tekniğine karar verilmesidir.

\section{KAYNAKLAR}

[1] Nath, R., Biggs, P.J., Bova, F.J., Ling, C.C., Purdy, J.A., van de Geijn, J., Weinhous, M.S. (1994). SYN45 : AAPM Code of Practice for Radiotherapy Accelerators, Report of AAPM Radiation Therapy Task Group, USA.

[2] Edward, C.H., Carlos, A.P., Luther, W.B. (2007). Perez and Brady's Principles and Practice of Radiation Oncology. Lippincott Williams\&Wilkins (ed.), 5. bask1, New York, USA.

[3] Hall, E.J., Giaccia, A.J. (2006). Radiobiology for the radiologist. Lippincott Williams\&Wilkins (ed.), 6. bask1, Philadelphia, USA.

[4] Carol, M.P. (1995). A system for planning and rotational delivery of intensity-modulated fields. International journal imaging systems technology, 6, 56-61.

[5] Ling, C.C., Burman, C., Chui, C.S. (1996). Conformal radiation treatment of prostate cancer using inversely-planned intensity-modulated photon beams produced with dynamic multileaf collimation. International Journal of Radiation Oncology Biology Physics, 35(4), 721-730.

[6] International Commission on Radiation Units and Measurements. (2010). Prescribing, Recording, and Reporting 
Photon-Beam Intensity-Modulated Radiation Therapy (IMRT), Oxford University, ICRU Report 83, UK.

[7] Carol, M.P., Targovnik, H., Smith, D. (1992). 3-D planning and delivery system for optimized conformal therapy. International Journal of Radiation Oncology Biology Physics, 24, 158.

[8] Mundt, A.J., Roeske, J.C. (2005). Intensity Modulated Radiation Therapy A Clinical Perspective. BC Decker (ed.), 5. bask1, Hamilton, USA.

[9] James, D.C., Kian, A. (2010). Radiation Oncology: Rationale, Technique, Results. Mosby Elsevier (ed.), 9. bask1, Philadelphia, USA.

[10] Paul, Q.M., Peter, H.R.E., Patrick, J.G. (2009). Principles and Practice of Head and Neck Surgery and Oncology. Informa healthcare (ed.), 2. bask1, New York, USA.

[11] Otto, K. (2007). Volumetric modulated arc therapy: IMRT in a single gantry arc. Medical Physics, 35(1), 310.

[12] Khan, F.M. (2003). The Physics of Radiation Therapy. Lippincott Williams\&Wilkins (ed.), 4. bask1, Philadelphia, USA.

[13] Khan, F.M., Gibbons, J.P. (2014). Treatment Planning in Radiation Oncology. Lippincott Williams\&Wilkins (ed.), 5. bask1, Philadelphia, USA.

[14] Lauve, A., Morris, M., Schmidt-Ullrich, R. (2004). Simultaneous integrated boost intensity-modulated radiotherapy for locally advanced head and neck squamous cell carcinomas: II clinical results. International Journal of Radiation Oncology Biology Physics, 60(2), 374-387.

[15] Mohan, R., Wu, Q., Manning, M., Schmidt-Ulrich, R. (2000). Radiobiological considerations in teh design of fractionation strategies for intensity-modulated radiation therapy of head and neck cancers. International Journal of Radiation Oncology Biology Physics, 46(3), 619-630.

[16] Bai, Y.R., Wu, G.H., Guo, W.J. (2003). Intensity modulated radiation therapy and chemotherapy for locally advanced pancreatic cancer: results of feasibility study. World Journal of Gastroenterol, 9(11), 2561-2564.

[17] Orlandi, E., Palazzi, M., Pignoli, E., Fallai, C., Giostra, A.,
Olmi, P. (2010). Radiobiological basis and clinical results of the simultaneous integrated boost (SIB) in intensity modulated radiotherapy (IMRT) for head and neck cancer. Critical Reviews in Oncology Hematol, 73(2), 111-125.

[18] Li, J.G., Xing, L., Boyer, A.L., Hamilton, R.J., Spelbring, D.R., Turian, J.V. (1999). Matching photon and electron fields with dynamic intensity modulation. Medical Physics, 26(11), 2379-2384.

[19] Radiation Therapy Oncology Group (RTOG), http://www. rtog.org/ClinicalTrials/ProtocolTable/StudyDetails.aspx, (16.05.2012).

[20] Schelegel, W., Bortfeld, T., Grosu, A.L. (2006). New Technoligies in Radiation Oncology. Springer (ed.), 1. bask1, Verlag, Berlin.

[21] Van’t Riet, A., Mak, A.C., Moerland, M.A. (1997). A conformation number to quantify the degree of conformality in brachytherapy and external beam irradiation: Application to the prostate. International Journal of Radiation Oncology Biology Physics, 37, 731-736.

[22] Krishnan, J., Rao, S., Hedge, S., Shetty, J., Shambhavi. (2015). A Dosimetric Comparison of Double Arc Volumetric Modulated Arc Therapy with Large Field Intensity Modulated Radiation Therapy for Head and Neck Cancer. International Journal of Medical Physics, 4, 353-363.

[23] Boylan, C., Rowbottom, C. (2014). A bias-free, automated planning tool for technique comparison in radiotherapy-application to nasopharyngeal carcinoma treatments. Journal of Applied Clinical Medical Physics, 15(1), 213-225.

[24] Syam Kumar, S.A., Vivekanandan, N., Sriram, P. (2012). A study on conventional IMRT and RapidArc treatment planning techniques for head and neck cancers. ScienceDirect, 17, 168-175.

[25] White, P., Chan, K.C., Cheng, K.W., Chan, K.Y., Chau, M.C. (2013). Volumetric intensity-modulated arc therapy vs conventional intensity-modulated radiation therapy in nasopharyngeal carcinoma: a dosimetric study. Journal of Radiation Research, 54, 532-545. 